\title{
SICKNESS AND STRESS IN OPERATIONAL FLYING
}

\author{
BY \\ D. D. REID \\ Lecturer in Medical Statistics, London School of Hygiene and Tropical Medicine, University of London. \\ Formerly Squadron Leader, Directorate-General of Medical Services, Royal Air Force
}

To the medical branch of an air force, the social or environmental conditions of pressing importance are the psychological stresses inevitable in air warfare. Only in war is it possible to observe the effects of such factors as acute hazard and intensive operational effort, with their resultant anxiety and fatigue, on the performance and well-being of such a highly selected population as the air crews of the Royal Air Force. Both the immediate effects of these stresses on efficiency and the long-term results in health were, therefore, the urgent concern of those whose duty it was to minimize these effects by every means open to the medical branch of a combatant force. The central issue was one of limitation of spells of duty-either short term, where the effects of hours of prolonged attention were to be forestalled, or long term, where the limits of an operational tour had to be set at a level high enough to ensure an adequate operational return for the training investment made yet not so long as to endanger health and morale. The problems of peacetime practice in social and industrial medicine are hardly as dramatic, yet the essential mechanism of the adjustment of men to the less hazardous but frequently harassing conditions of post-war life are identical. This account of some typical studies of sickness in relation to measurable environmental and personal factors is given in the hope of displaying the potentialities of the methods used in the study of problems of sickness and morale in an industrial population.

Research on duty limitation in the R.A.F. during the war had a tripartite approach by clinical, laboratory, and field surveys. The clinical studies have been described by Symonds (1943), the laboratory work by Russell Davis (1948); in the present paper is set out an application of statistical methods to data collected in the course of active operations in the field.

\section{Background of Present Study}

The background to the present studies may be briefly sketched. In the world war 1914-18, work was mainly along clinical lines, the opinions expressed (Birley, 1920) being intuitive judgments based on extensive experience with cases of neurosis occurring in the operational squadrons. The importance of the hazardous, fatiguing, and often physically exhausting nature of flying duties was recognized, but the issue was clouded by a preoccupation with the cumulative effects on health and performance of the physical stresses specific to flight, such as oxygen lack, and others less specific such as cold, noise, discomfort, and glare. A tendency to overstress the importance of the presumed cumulative effects of the stresses of air fighting as a cause of breakdown in flying men persisted until the world war 1939-45, and with it the implication that a simple relation existed between the number of hours' flying done and the resultant degree of deterioration in health and efficiency. Thus in the short term context, efficiency would fall off towards the end of an operational sortie, while in the long run, signs and symptoms of impending breakdown were to be looked for after a prolonged tour of many sorties.

Contrary indications, however, came from laboratory experiments recently described by Russell Davis (1948) where, in a complex and distracting experimental situation analogous to flying, no progressive deterioration in efficiency was observed. On the other hand it became clear that anxiety and tension had much more serious effects on the level of performance. This was strikingly confirmed by an analysis of the errors made by navigators of bomber aircraft during sorties against German targets (Reid, 1947). The effect of anticipatory anxiety was seen in a steady deterioration in efficiency on the outward journey, particularly over the enemy coast, and on approaching the target. This effect reached a maximum in the acute anxiety engendered by heavy enemy fighter opposition and persisted as long as the aircraft was over enemy territory. Compared with this, any effect of " fatigue," in its conventional sense of deterioration at the end of prolonged activity, was minimal. Similarly, Bradford Hill and G. O. Williams (1943) showed that landing accidents were no more common after long sorties than after much shorter ones.

Clinical studies by Symonds and D. J. Williams 
(1947) on the histories of cases of neurosis arising in the operational Commands demonstrated that the bulk of them were men of neurotic predisposition who broke down early in their operational career. There did remain, however, many instances of breakdown after prolonged stress among men of the toughest fibre. Tour limitation, therefore, was essential, and in the formulation of policy in this matter the precision of statistical methods complemented the insight of the clinical approach. A search for objective measures of the process of adaptation to stress during the course of an operational tour showed that the critical nature of the early part of the tour was revealed by a simultaneous increase in the incidence of psychological disorder and the frequency of reporting sick and a fall in the average weight of a large group of flying men (Reid, 1947). As adjustment to the strain took place, these three indicators tended to stabilize at a new level and showed no sign of deterioration towards the end of a tour limited to thirty bomber sorties. The possibility of using such measures in the determination of optimum tour limits was thus evident, but there remained the task of discerning the relative importance of such measurable environmental factors as hazard, experience, and effort in the maintenance of health in men exposed to their effects. These relationships could then be taken into account in laying down the broad principles of tour limitation.

\section{OUtLINE OF MeTHOD}

In such a study, the effects of these measurable external factors in health and morale were assessed by the varying incidence of neurosis and venereal disease among the flying crews. Men react differently to strain; some find refuge in neurotic illness, while in others the weakening is one of morals rather than of morale. With the monthly incidence of these two types of illness as criterion, then, the relative importance of any environmental factor can be gauged by the closeness of the association between its varying intensity and the fluctuations in the incidence of nervous and venereal disease.

As Bomber Command formed the largest body of men in the R.A.F. engaged in operational flying of a particularly hazardous and strenuous character, the vital and operational statistics of the five major Groups of this Command were studied for a period of twenty months from June, 1943, to January, 1945, inclusive. Product moment coefficients of correlation were calculated between the criteria and various items believed to indicate the magnitude of the several environmental factors of importance. The conventions adopted may be briefly set out.

\section{Criteria of Effects of Stress}

Neurosis.-The incidence of psychological dis- $\frac{2}{8}$ order is taken as the percentage of the average air $?$ crew strength for any month who were referred $\overrightarrow{\vec{\rho}}$ during that month for psychiatric opinion because $\vec{\sigma}$ of psychological disorder. It might have been preferable to assign these cases to the month in which $\bar{c}$ they became non-effective. As the delay between $\mathbb{\widetilde { D }}$ the latter date and the date of the first psychiatric interview is normally fairly short, however, this कs should affect the extent rather than the nature of $\overrightarrow{0}$ the relationships between the incidence of neurosis and the items investigated. Similarly, it was $\omega_{\sigma}$ impossible to account for cases of psychological $\frac{2}{\circ}$ disorder dealt with on the stations without being $)$ referred to the psychiatrist. This, too, may lessen ? the closeness of the correlation, but it should not hide any striking relationship which does exist.

Venereal Disease.-Similarly, the incidence of $\mathrm{C}$ venereal disease is taken as the percentage of the average air crew strength reported as fresh cases of $O$ venereal disease during the month in question.

\section{Measures of EnVIRonmental Factors}

Hazard.-The hazard or degree of personal danger $\varphi$ to which crews are subject in any month is begt measured by the casualty rate through operationt causes, i.e. in battle or in flying accidents, in thes month. This hazard rate is the percentage of the average monthly crew strength who become casual- $\%$ ties during the month. The cumulative effect of $\stackrel{\mathbb{Q}}{\complement}$ hazard is taken into account by calculating the $\overrightarrow{\overrightarrow{0}}$ correlation coefficient between the neurosis incidence 3 in one month and the casualty rate both in the same month and in the month before.

An alternative method of measuring the degree of hazard is to calculate the average number of aircraft $\stackrel{\rho}{?}$ lost through enemy action in the course of every hundred sorties carried out by the Bomber Group. in the month. This percentage has been termedo the " missing per sortie " rate. It depends in part, of course, both on the effectiveness of the enemy의 opposition and on the skill of the crews' defensive $>$ tactics. To some extent it is thus a measure of their operational efficiency. It is also a measure of the N rate at which casualties are occurring rather than the - total casualties suffered during the month.

Inexperience. - The level of operational experience $N$ of the Group is quite easily measured by calculating the percentage of the average crew strength for theo month who have been posted into the Group, on $\Phi$ completion of training, during the month. In ? other words, this percentage expresses the proportion of the squadrons' strength who are novices to $\frac{\text { P }}{\mathbb{D}}$ operational flying. 
Effort.-The cumulative effect of long hours of highly skilled activity should be reflected in an association between the incidence of neurosis and features of squadron employment to which fatigue is often attributed. Among these are the average number of flying hours per individual in each month and/or the frequency and average duration of the sorties occurring during that month. The total number of hours, operational and non-operational, flown each month by all the aircraft in the Group, and the average number of men on board being known, it is easy to calculate the mean number of flying hours done by each man in each month. The frequency with which each man operated, i.e. the average number of sorties per man per month, is calculated in the same way from the total number of aircraft sorties carried out by the Group in the month in question. Similarly, the number of operational hours and the number of sorties carried out by the Group in any one month being known, simple division of the former by the latter gives the average duration of sortie during that month. As when dealing with the effect of hazard, the cumulative effect of the operational effort from one month to the next can be gauged by the correlation between the flying time and sortie duration and frequency averages for one month and the incidence of neurosis in the next.

\section{Summary OF RESUlTS}

For security reasons it is unfortunately impossible to give in detail the figures upon which these measures are based, but they derive from the experience of the whole of Bomber Command at a period of its maximum strength. The.correlation coefficients indicating the relationship between these measures and the criteria are given in Table I where they are arranged in order of their magnitude under the headings as previously defined.

For venereal disease, similar results were obtained; the only significant correlations were between the venereal disease incidence and the casualty and inexperience groups of items (Table II).

It would appear from these correlation coefficients that only hazard and inexperience are significantly related to the selected criteria of the effects of operation strain. There is no evidence of such a clear relationship between the criteria in the " effort" group of items; yet these items may be fairly termed " fatiguing" in that they might be expected to have a cumulative effect on the mental health of the crews. It is clear that the monthly variation in " effort" in this study has not had an appreciable effect on the monthly incidence of neurosis.

Some allowance must be made for the association between the influx of new crews in any one month and the heavy casualty rate sustained by these operationally inexperienced men in the succeeding month. At the same time, in the latter month, these men reach the critical stage in their tour when breakdown is most likely. The association between the neurosis rate and the casualty rate in any month may therefore be merely an expression of their common relationship to the novice rate in the

TABLE I

CORRELATION BETWEEN Items and Neurosis Rate

A. " Hazard" group of items

1. Casualty rate (in same month)

2. Casualty rate (in previous month)

3. Missing per sortie rate (in previous month)

4. Missing per sortie rate (in same month)

B. "Inexperience" group of items

1. Novice rate (in same month)

2. Novice rate (in previous month)

C. " "Effort" group of items

1. Total flying hours per man (in previous month)

2. Total flying hours per man (in same month)

3. Average sortie duration (in previous month)

4. Average sortie duration (in same month)

5. Operational flying hours per man (in previous month) :

6. Average frequency of sorties per man (in previous month)

7. Average frequency of sorties per man (in same month) ..

8. Operational flying hours per man (in same month)

\begin{tabular}{|c|c|c|c|c|}
\hline & & & & $\mathrm{r}=$ \\
\hline . & .. & .. & .. & $0.4194 \mathrm{xx}$ \\
\hline . & . & & .. & $0 \cdot 3312 \mathrm{xx}$ \\
\hline$\cdot$ & . & $\cdots$ & $\cdots$ & $0.2455^{\circ} x$ \\
\hline & & .. & $\cdots$ & $0 \cdot 2404 \times$ \\
\hline
\end{tabular}

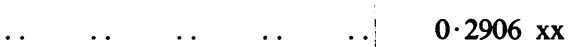

$0 \cdot 2869 \mathrm{xx}$

$0 \cdot 1163$

$0 \cdot 1157$

0.0933

0.0351

0.0323

0.0267

$0 \cdot 0029$

0.0019 
A. "Hazard" group of items

1. Casualty rate (in previous month)

2. Casualty rate (in same month)

B. "Inexperience" group of items

1. Novice rate (in same month)

2. Novice rate (in previous month)

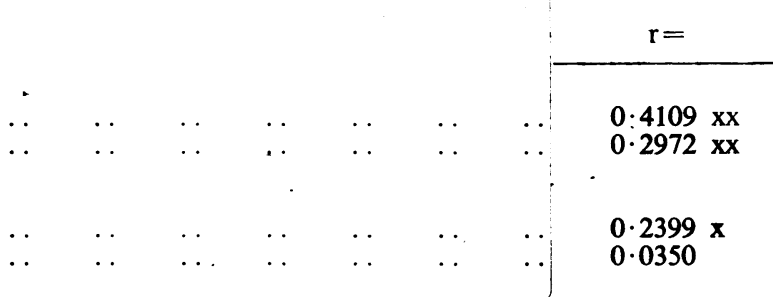

$x x$ denotes highly significant relationship, $\mathbf{P}<\cdot 01$.

$x$ denotes a significant relationship, $P<\cdot 05$.

previous month. Fortunately this possibility can be taken into account by calculating the partial or net correlation between the casualty rate and the neurosis rate in any month when the novice rate in the previous month is kept constant. The value obtained $(r=0 \cdot 3734)$ shows that the casualty rate in any month is significantly more closely associated with the neurosis rate than might be explained by their common relationship to the proportion of inexperienced crews. Similarly, there exists a significant net correlation between the novice rate in any month and the neurosis rate in the next, even after eliminating the effect of simultaneous variations in the casualty rate $(r=0 \cdot 2044)$. The experience in venereal disease is analogous; the net correlation between the casualty rate in one month and the venereal disease rate in the next is, when the novice rate is kept constant, significantly high $(r=0 \cdot 3546)$. On the other hand the net relationship between the novice rate and the venereal disease rate becomes insignificant $(r=0 \cdot 1292)$ when simultaneous fluctuations in the casualty rate are taken into account.

The position may be summarized by suggesting that although correlation, particularly in a time series such as this, does not necessarily mean causation, the hazard of operational flying has both an immediate and delayed effect on the incidence of both neurotic and venereal disease. The immediate effect is most marked on neurotic illness; the delayed effect, probably as the result of the delay in obtaining opportunities for infection and the incubation period of gonorrhoea (the most frequent type), was more definite in venereal disease. Further, the immediate response to the realization of the dangerous nature of their duty was reflected in an increase in neurosis, particularly among the inexperienced men, but the rise in venereal disease was not particularly frequent among operational novices.

\section{Practical Consequences of Results}

Of the measurable environmental factors affecting health and morale, operational hazard is thus $\mathrm{\omega}$ clearly of decisive importance. Conversely, factors 음 such as the number of flying hours done by each man and the frequency of operating do not produce $O$ the cumulative effect on mental health which $\frac{?}{0}$ conventional ideas about " fatigue" might have led $\frac{\bar{\Phi}}{\square}$ one to expect. In laying down a policy of tour

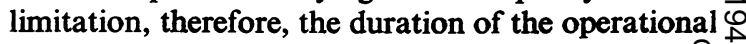
tour to be expected from those who survive lon 9 enough to become due for relief must take these facts into account. No arbitrary number of flyis hours can be taken as the optimum limit in all types of flying. Since the number of hours flown does not in itself determine the incidence of neurosis, $\stackrel{\mathbb{Q}}{\mathscr{Q}}$ it would be unrealistic to translate a tour limit of $\overrightarrow{\overrightarrow{\vec{A}}}$ $x$ hours from, say, long-range flying boat sea patrols $\frac{3}{3}$ to the conditions of intensive fighter operations. Tour limits may be expressed in flying hours, but they had to be framed to take into account the hazard involved in the particular type of flying in $\frac{\AA}{\supset}$ question. The basic principle adopted was the setting of the limit at a level giving the individual 3 . a chance of surviving the particular hazards entailed $\delta$ which could be faced without breakdown in health and morale by the resolute type of man who elected 0 to serve in the air. Exactly what that limit should have been was difficult to assess. Within the range $\frac{\text { o }}{2}$ of casualty rates experienced by Bomber Command ${ }_{N}$. during the period reviewed, there appeared to be no? point-beyond which a sudden serious deterioration $\tilde{O}$ took place. The physical measures of health $\mathbb{E}$ already mentioned gave no indication of a decline 0 in health among those who survived the initial period of adaptation. On the other hand, the $\frac{\bar{\Phi}}{\Phi}$ hazard of bomber operations was such that the $\stackrel{?}{+}$ incidence of neurosis in Bomber Command was 0 higher than in any other Command of the Royal Air Force (Symonds and Williams, 1947). The 
" expectation of life" prevailing in that Command could, therefore, be taken as a minimum rather than an optimum for general application and the duration of the operational tour in other forms of combat flying set to ensure that the individual pilot had at least the same chance of survival as was general in the bomber offensive against German targets.

\section{Sickness on Sorties: a SPECIFIC ENQUiRy}

Useful as these general indications were, the size of the multiple correlation coefficient between neurosis, and hazard and inexperience $(R=0 \cdot 4585)$ suggests that these factors accounted for only about 21 per cent. of the total amount of variance in the incidence of neurosis. They take no heed of intangibles such as squadron leadership and personal morale. Tour limits can be laid down very broadly, but in their application to an individual case the complex of relevant personal and environmental features must be resolved by the squadron commander, aided by his medical officer, in determining the best time of relief from further operational duties.

Typical of the problems met with by the squadron doctor was the case of sickness causing the abandonment or cancellation of an operational sortie. This was an unusual event (it happened about once in every 5,575 person-sorties), so that no single medical officer could acquire the body of clinical experience needed to frame a sound prognostic judgment. Yet, if no obvious physical reason for the sickness was present, two questions rose urgently in the mind of the squadron doctor:

(a) Is this sickness likely to be a portent of impending breakdown?

(b) Does the return to full duty of this man, whose morale and efficiency may be suspect, entail an increased hazard for the aircraft in which he is flying?

To assess the prognostic significance of the basic patterns of reaction observed, statistical studies were made of a series of such cases occurring in Bomber Command.

\section{OUTLINE OF METHOD}

The nature of the two critical questions implies that some follow-up of the subsequent operational careers of the sick men is required. Not only must their own medical and operational histories be obtained and analysed, but a suitable standard of comparison must be afforded. This was effected in practice by making a series of paired comparisons between the "sick" case and a corresponding "control" man selected from among the others in the squadron. From the Squadron Weekly Aircrew List for the week in which the sickness occurred was selected a "pair" for the man whose illness during or just before a sortie had caused its abandonment or cancellation. This "control" man was selected as far as possible so that each pair was comparable in respect of these items in the following order of priority: (1) crew duty; (2) number of sorties performed before the date of the sickness; (3) squadron; (4) officer or non-commissioned officer status. Thus it was hoped to control the influence on morale and efficiency of such factors as the stresses specific to the task in the air, operational experience, squadron leadership, and living conditions. In other words, during their subsequent careers in the squadron, both the "sick" man and his "control" were subject to the same environmental influences and differed only in the one respect of this particular type of sickness. In a group of such pairs, the differences between their subsequent performance should therefore be due mainly to differences in the psychological qualities of the individuals themselves, since both men in each pair are equally likely to be affected by the chances and hazards of flying in war.

The subsequent operational career of each of the men thus paired was followed up through the records of the Personnel Staff sections in each Group Headquarters. Two features were examined in particular:

(1) the cessation of flying duties through illness, whether physical or psychological;

(2) the survival time subsequent to the date of sickness, measured for each man of the pair by the number of sorties completed.

These features were recorded together with all the relevant medical data about the sick case, on cards which could then be sorted into groups. The manner of this division depended on the factor being studied, for example, nature of symptom pattern, previous operational experience, etc. Intergroup as well as inter-pair differences could thus be investigated and the relative prognostic importance of both sickness in general and of some additional factor, such as experience, assessed: The statistical methods involved are detailed in the appropriate tables in each section.

In the clinical assessment of the likelihood of a psychological basis for the complaints which necessitated the return of the aircraft, full weight would be given to definite physical signs of disease; but in so many of these cases no such definite aid is forthcoming and the medical officer must rely upon a subjective account of the symptoms. In order to assay the relative prognostic importance of various 
types of symptom pattern, the pairs of sick cases and their controls were divided up on the basis of an arbitrary grouping of the presenting symptoms.

1. Syncope.-All cases where the patient lost consciousness were taken separately. These cases were divided into:

(a) those where the fainting was clearly due to a failure of the oxygen supply;

(b) those where no defect of the oxygen apparatus could be found. Fainting was here usually preceded by dizziness, defective vision, and vomiting, and often followed by stupor.

2. Nervous.-Cases in which fainting did not occur but where symptoms referable to the nervous system were complained of, were next classified together. These symptoms fall broadly into two groups, the first dealing with intellectual and emotional disturbance and the second with more specific physical complaints. These grades may be described in more detail:

(a) inability to concentrate, lack of confidence in his ability to carry out his duty, frank admissions of panic or fear, feelings of anxiety or acute depression perhaps accompanied by weeping;

(b) dizziness, blurring of vision, complaints of confusion, fatigue or " muzziness," faintness without loss of consciousness, neuritic pains, muscular weakness, backache, "pins and needles," sweating and rapid breathing.

3. Alimentary.-Nausea, epigastric pain, heartburn, waterbrash, vomiting, colic.

4. Airsickness.-Cases were classified as airsickness only when there was a clear previous history of airsickness.
5. Respiratory (and ear, nose, and throat).Painful ears, sinus pains, cough, breathlessness, asthma.

6. Injuries.-Usually minor injuries, received just before take off.

In following up the operational careers after the date of sickness, partícular note was taken of the reasons for cessation of full flying duties. Medical reasons for becoming non-effective might be physical or psychological. "Psychological reasons" have here been extended to include not only frank neurotic disorder but also executive disposal, for example, on grounds of "lack of moral fibre." The prognostic importance of any feature of the group being studied will therefore be indicated by the disparity between the proportion of subsequent psychological failures in the " sick" and " control" series of paired cases.

\section{Summary OF Results}

Table III shows the wastage rates for physical and psychological reasons in each of the symptom pattern groups already described.

Inspection of the final percentages in Table III shows that although the wastage for physicad $\$$ reasons in the " sick" group ( $6 \cdot 5$ per cent.) is largeश than in the "controls" ( 3.2 per cent.), this dis parity is not nearly so striking as the difference between the corresponding psychological wastages rates of 23.2 per cent. and 0.6 per cent. Prognostic importance being measured by the extent of this -disparity, the syndrome sets can be classified by the size and significance of the difference in psychological wastage rates between the "sick" and " control " group in each syndrome set. Table IV shows how the syndromes may be thus divided into

TABLE III

Physical and Psychological Wastages in Symptom Groups

\begin{tabular}{|c|c|c|c|c|c|c|c|c|c|c|c|}
\hline & & & \multirow{3}{*}{$\begin{array}{l}\text { No. of } \\
\text { Pairs }\end{array}$} & \multicolumn{4}{|c|}{ Physical wastage } & \multicolumn{4}{|c|}{ Psychological wastage } \\
\hline & & & & \multicolumn{2}{|c|}{ Sick } & \multicolumn{2}{|c|}{ Control } & \multicolumn{2}{|c|}{ Sick } & \multicolumn{2}{|c|}{ Control } \\
\hline & & & & No. & $\%$ & No. & $\%$ & No. & $\%$ & No. & $\%$ \\
\hline 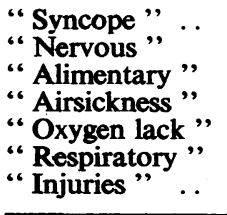 & $\begin{array}{l}\ldots \\
\cdots \\
\cdots \\
\cdots \\
\cdots \\
\cdots\end{array}$ & $\begin{array}{l}. \\
. \\
. \\
. \\
. \\
. \\
.\end{array}$ & $\begin{array}{r}19 \\
31 \\
47 \\
7 \\
9 \\
34 \\
8\end{array}$ & $\begin{array}{l}0 \\
2 \\
1 \\
0 \\
0 \\
7 \\
0\end{array}$ & $\begin{array}{r}0 \cdot 0 \\
6 \cdot 5 \\
2 \cdot 1 \\
0 \cdot 0 \\
0 \cdot 0 \\
20 \cdot 6 \\
0 \cdot 0\end{array}$ & $\begin{array}{l}0 \\
2 \\
1 \\
1 \\
0 \\
1 \\
0\end{array}$ & $\begin{array}{r}0 \cdot 0 \\
6 \cdot 5 \\
2 \cdot 1 \\
14 \cdot 3 \\
0 \cdot 0 \\
2 \cdot 9 \\
0 \cdot 0\end{array}$ & $\begin{array}{r}15 \\
9 \\
6 \\
1 \\
2 \\
3 \\
0\end{array}$ & $\begin{array}{r}78 \cdot 9 \\
29 \cdot 0 \\
12 \cdot 8 \\
14 \cdot 3 \\
22 \cdot 2 \\
8 \cdot 8 \\
0 \cdot 0\end{array}$ & $\begin{array}{l}\mathbf{0} \\
0 \\
0 \\
0 \\
1 \\
0 \\
0\end{array}$ & $\begin{array}{r}0.0 \\
0.0 \\
0.0 \\
0.0 \\
11.1 \\
0.0 \\
0.0\end{array}$ \\
\hline Totals & .. & . & 155 & 10 & $6 \cdot 5$ & 5 & $3 \cdot 2$ & 36 & $23 \cdot 2$ & 1 & 0.6 \\
\hline
\end{tabular}


those which are significantly related to the chance of subsequent psychological failure and those where the differences might well be due to chance. Further, the former group may be placed in order of importance by the extent of this disparity.

Table IV shows that although there is a consistent tendency for those who have been sick on a sortie to incur a later psychological disability, this tendency is only significant in three syndrome groups" syncope," "nervous," and " alimentary" -in that order. It should also be noted that only the first of these is anything like a certain indicator of psychological breakdown. Other features of each individual case, operational experience and time of onset, must therefore be considered as in Tables $\mathrm{V}$ and VI.

This division of the cases into groups according

TABLE IV

Symptom PatTern and Disparity in Psychological WASTAGE RATES

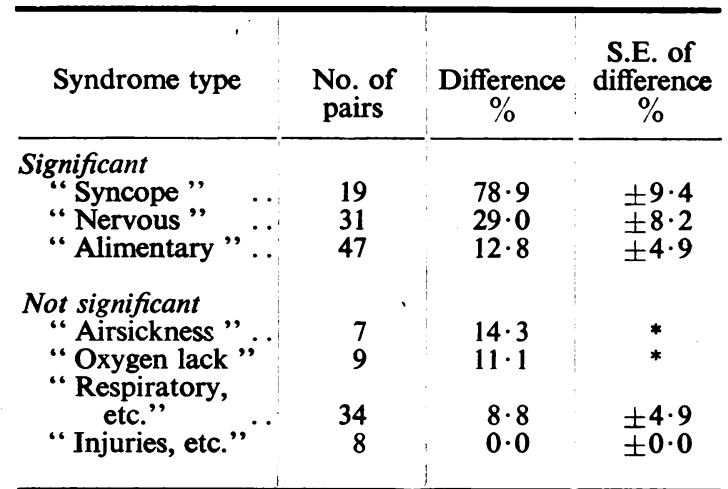

* Exact treatment of these small samples shows the difference to be insignificant.

to the number of sorties completed prior to the date of sickness shows that the psychological wastage rates rise to a maximum early in the tour, that is, that sickness occurring during the first ten sorties is much more likely to be psychogenic than if it arises later in the tour (a table comparing the numbers of wastages among sick men who had done less than ten sorties and the remainder gives $\left.\chi^{2}=5 \cdot 0763, n=1, \cdot 05>P>0 \cdot 02\right)$. This, of course, is in keeping with the previous work which demonstrated the increased effects of stress on the operationally inexperienced.

Similarly, the importance of the stage in the particular sortie at which symptoms arose is evident in Table VI. The original reports of these sicknesses showed not only the time of take-off but also the time of onset of symptoms. The difference between those times thus indicates the stage in the
TABLE V

INTERRELATION OF OPERATIONAL EXPERIENCE AND SUBSEQUENT HISTORY

\begin{tabular}{|c|c|c|c|c|c|}
\hline \multirow{3}{*}{$\begin{array}{l}\text { Operational } \\
\text { experience } \\
\text { in sorties }\end{array}$} & \multirow{3}{*}{$\begin{array}{l}\text { No. of } \\
\text { pairs }\end{array}$} & \multicolumn{4}{|c|}{ Psychological wastage } \\
\hline & & \multicolumn{2}{|c|}{ Sick } & \multicolumn{2}{|c|}{ Control } \\
\hline & & No. & $\%$ & No. & $\%$ \\
\hline $\begin{array}{l}0-3 \\
4-9 \\
10-19 \\
20+\end{array}$ & $\begin{array}{l}39 \\
41 \\
46 \\
29\end{array}$ & $\begin{array}{r}10 \\
15 \\
9 \\
2\end{array}$ & $\begin{array}{r}25.6 \\
36.6 \\
19.6 \\
6.9\end{array}$ & $\begin{array}{l}0 \\
0 \\
1 \\
0\end{array}$ & $\begin{array}{l}0 \cdot 0 \\
0 \cdot 0 \\
2 \cdot 2 \\
0 \cdot 0\end{array}$ \\
\hline Total & 155 & 36 & $23 \cdot 2$ & 1 & 0.7 \\
\hline
\end{tabular}

sortie or distance out from base when the symptoms were first observed.

Table VI shows that although most of the sickness occurs early in the sortie, the chance of subsequent psychological failure rises consistently in each successive stage of the sortie. This suggests (although the $X^{2}$ value of $5 \cdot 3679, \mathrm{n}=2, \cdot 10>\mathrm{P}>\cdot 05$ is barely technically significant), that illness arising later in the sortie is more likely to have a psychological basis than sickness occurring either at take-off or in the first half-hour. In the previous study on navigator performance it was observed that efficiency fell off as the enemy coast was approached, presumably due to the increasing effects of anticipatory anxiety. It seems likely that this effect is becoming apparent in the increased likelihood of psychogenic upset occurring as the sortie progresses.

All three factors, then, symptom pattern, operational experience, and stage in sortie, are probably related to the likelihood of psychological failure in the subsequent flying career. Despite this association, however, it does not necessarily follow

TABLE VI

Time of ONSET AND Subsequent History

\begin{tabular}{c|c|c|c|c}
\hline $\begin{array}{c}\text { Stage in } \\
\text { Sortie } \\
\text { (flying } \\
\text { time in } \\
\text { minutes) }\end{array}$ & $\begin{array}{c}\text { No. of } \\
\text { cases }\end{array}$ & $\begin{array}{c}\text { \% of total } \\
\text { cases }\end{array}$ & \multicolumn{2}{|l}{ Psychological wastage } \\
\cline { 2 - 4 } & & & No. & $\%$ \\
\hline $0-9$ & 45 & $29 \cdot 0$ & 7 & $15 \cdot 6$ \\
$10-29$ & 20 & $12 \cdot 9$ & 3 & $15 \cdot 0$ \\
$30-39$ & 23 & $14 \cdot 9$ & 6 & $26 \cdot 1$ \\
$40-59$ & 27 & $17 \cdot 4$ & 6 & $22 \cdot 2$ \\
$60-90$ & 27 & $17 \cdot 4$ & 9 & $33 \cdot 3$ \\
$90+$ & 13 & $8 \cdot 4$ & 5 & $38 \cdot 5$ \\
\hline Total & 155 & $100 \cdot 0$ & 36 & $23 \cdot 2$ \\
\hline
\end{tabular}


that each of these factors can be taken as independent items of clinical evidence in formulating a prognostic judgment. If one factor overlaps much with another, for example if all cases of syncope occurred in the later stages of the sorties, then taking stage of sortie into account would not enhance the accuracy of a prognosis based on our experience of syncope cases alone. On the other hand if the two are not related, then one can legitimately consider the stage of sortie as additional information of prognostic value. The contingency tables giving the relationships between each of the three factors are not reproduced, but they suggest that there is no significantly close relationship between them; this is confirmed in each instance by the $\chi^{2}$ test. It follows, then, that in any individual case the information relevant to each of these three aspects can be combined in framing an estimate of the likely outcome of the patient's subsequent operational career.

The risk entailed in allowing a man who has suffered from a sickness which might well be psychogenic to go back to operational duty can be measured by the difference, if any, in the number of sorties subsequently completed by the "sick" compared with the " control " member of the pair in the same squadron at the same time. Any gross disparity in favour of the controls would imply that the return of the " sick" men to their operational duties entailed an increased hazard for the aircraft in which they flew. The differences actually observed are given in Table VII.

As Table VII indicates, there is a slight adverse difference in the total number of sorties subsequently performed in the group who went on operating even after a sickness of a type normally associated with a liability to psychological failure. The " $t$ " test for the significance of this mean difference between pairs indicates, however, that the difference might easily have occurred by chance. Further subdivision of the cases was hardly justified by the numbers involved, so that it must be concluded from these

TABLE VII

Comparison of Subsequent Operational Survival TIME IN SORTIES

\begin{tabular}{l|c|c|c}
\hline & $\begin{array}{c}\text { No. of } \\
\text { cases }\end{array}$ & $\begin{array}{c}\text { Sorties subsequently completed } \\
\text { ("Sick" } v . " \text { "Control ") }\end{array}$ \\
\cline { 2 - 4 } & & $\begin{array}{c}\text { Mean } \\
\text { difference }\end{array}$ & $\begin{array}{c}\text { S. error of } \\
\text { difference }\end{array}$ \\
\hline $\begin{array}{l}\text { S.N.A.* } \\
\text { Others }\end{array}$ & 63 & $\begin{array}{l}-1 \cdot 35 \\
+2 \cdot 14\end{array}$ & $\begin{array}{l} \pm 1.48 \\
\pm 1.68\end{array}$ \\
\hline
\end{tabular}

" S.N.A.-" Syncope," "Nervous" and " Alimentary" disorders. results that if a man carried on without breakdown after an illness in the air which might well have been psychogenic in origin, his presence in the crew did not seem to affect appreciably the aircraft's chance of safe return in subsequent sorties.

\section{Discussion}

These studies are typical of the field research which formed a useful complement to clinical and laboratory work in war medicine. They are important for the confirmation which they gave in this instance to the suggestion that anxiety was more important than prolonged effort as a cause of deterioration in health and operational efficiency. Essentially statistical in methodology, they show how the numerical approach can be a useful adjunct to the clinical or impressionistic methods which rely upon the intuitive judgments of the skilled observer and to laboratory work where realism must so often be sacrificed to technical convenience.

The recognition and measurement of the effects of the mental stresses inherent in the operational environment is important in war; the physical conditions of battle may change, but the principles of action in human behaviour remain. But these methods and results, though useful in war, may be none the less useful in peace. Admittedly we have dealt with the effects of particularly severe strain on a highly selected group, but the principles probably hold for the results in the less resilient population of a factory of the far from negligible emotional stresses of industrial life. The many-sided aspect of the reaction to stress-the failing efficiency, the objective signs of physical deterioration, and the characteristic symptom patterns-calls for an equally varied taste in the methods used in such studies.

If Service experience such as here described be taken as a guide, it would appear that the convergent attack on a single problem by workers skilled in clinical, laboratory, and statistical field research is a useful approach to the difficulties of investigation in social medicine.

\section{SUMmary}

This paper describes typical field studies, carried out in Bomber-Command of the Royal Air Force during the war 1939-45, on the effects of operational stresses both on the incidence of certain diseases and in individual cases of sickness occurring in the course of bomber operational sorties.

A study of the relationship between the incidence of neurosis and venereal disease and various indices of operational hazard and effort suggests that the ácute anxiety caused by a high casualty rate had a 
much more decisive effect on health and morale than had prolonged or intensive operational effort.

Operational inexperience which also plays a part in determining the incidence of neurosis, is shown to be relevant in the prognosis of cases of sickness occurring in conditions of acute stress on operational sorties. The chance of subsequent psychological failure in such cases is also seen to have been related to the type of presenting syndrome and the stage in the sortie at which the sickness appeared. Fainting and symptoms referable to the nervous and alimentary systems, particularly if they arose some time after take-off, were indicative of impending breakdown. In those instances where this did not occur, however, no extra risks to the aircraft in which he flew were incurred by allowing the man to continue on operational duty.

These suggestions of the predominant effects of anxiety over "fatigue" (in the sense of the end results of prolonged effort) can be related to the findings of laboratory and clinical research done in the Royal Air Force. The value of simple statistical methods in field research as a complement to laboratory and clinical studies is discussed.
I am indebted to Air Marshal Sir Harold Whittingham, Director General of Medical Services of the Royal Air Force during the war, for his encouragement, to the Consultants in Neuropsychiatry and Medical Statistics, Sir Charles Symonds and Prof. A. Bradford Hill for their direction and advice, and to the present Director General of Medical Services, Royal Air Force, Air Marshal P. C. Livingston, for permission to publish this work. My thanks are also due to Miss O. M. Penfold, formerly Corporal W.A.A.F., for secretarial and computing assistance.

\section{REFERENCES}

Birley, J. L. (1920). Lancet, 1, 1147.

Davis, D. Russell (1948.) "Pilot Error." Air Ministry A.P. 3139a. H.M.S.O.

Hill, A. Bradford, and Williams, G. O. (1943). Investigation of Landing Accidents in relation to Fatigue. Flying Personnel Research Committee Report No. $423(\mathrm{~m})$

Reid, D. D. (1947). " Some Measures of the Effect of Operational Stress on Bomber Crews." Air Ministry A.P. 3139, 245-258. H.M.S.O.

- (1947). "Fluctuations in Navigator Performance during Operational Sorties." Air Ministry A.P. 3139, 321-329. H.M.S.O.

Symonds, C. P. (1943). Brit. Med. J., 2, 703 and 740.

- and Williams, D. J. (1947). "Clinical and Statistical Study of Neurosis Precipitated by Flying Duties." Air Ministry A.P.3139, 140-172. H.M.S.O. 